\section{B A Institute of \\ YK Business Administration \\ 光 \\ Karachi \\ Leadership and Ideas for Tomorrow}

\section{Business Review}

Volume 8 Issue 2 July-December 2013

$7-1-2013$

\title{
Using metaphors in strategy formulation
}

\author{
Naveed Yazdani \\ University of Management \& Technology, Lahore, Pakistan \\ Ayesha Gulzar \\ University of Management \& Technology, Lahore, Pakistan
}

Follow this and additional works at: https://ir.iba.edu.pk/businessreview

Part of the Organizational Behavior and Theory Commons, and the Strategic Management Policy Commons

\section{(c) (i)}

This work is licensed under a Creative Commons Attribution 4.0 International License.

\section{Recommended Citation}

Yazdani, N., \& Gulzar, A. (2013). Using metaphors in strategy formulation. Business Review, 8(2), 30-41. Retrieved from https://doi.org/10.54784/1990-6587.1284

This article is brought to you by iRepository for open access under the Creative Commons Attribution 4.0 License and is available at https://ir.iba.edu.pk/businessreview/vol8/iss2/3. For more information, please contact irepository@iba.edu.pk. 


\title{
ARTICLE
}

\section{Using Metaphors in Strategy Formulation}

\author{
Naveed Yazdani \\ University of Management \& Technology, Lahore, Pakistan \\ Ayesha Gulzar \\ University of Management \& Technology, Lahore, Pakistan
}

\begin{abstract}
This theoretical paper focuses on brain as a metaphor for studying the process of strategy formulation. The paper argues that when individuals within organizations use brain to self-reflect the uncertainty in the environment, the organization are in better position to meet the competitive advantage.
\end{abstract}

Key Words: Metaphor, Brain, Strategy formulation

\section{Introduction}

Ascribing to the social existence of the organizations (Stinchcombe, 2000; Weber, 1997) the human beings are the building blocks of organizations and in this view organizations are social entities (Broom, Casey, \& Ritchey, 1997; Ringberg \& Reihlen, 2008; Selznick, 1948). Whenever people come close to achieving certain goals they create organization. So, an organization refers to a person or group of people that are on purpose organized to achieve an overall, common goal or set of goals. Hence the organizations are social entities that work and sustain their operations in a social context (Broom et al., 1997; McAuley, Duberley, \& Johnson, 2007). There are several significant features to consider about the goals of the business organization(Drazin, Glynn, \& Kazanjian, 1999; Dutton, Dukerich, \& Harquail, 1994). These characteristics are explicit or implicit. These characteristics are carefully considered and established, during the process of strategic planning(Daft \& Wiginton, 1979; Downs, Durant, \& Carr, 2003; Mehregan, Kahreh, \& Yousefi).Members of the organization often have some image in their minds(Calvin, 1990) about, how the organization should be working, how it should appear when things are going well (Morgan, 1980, 1983). The explicit goals are quite clear and easy to understand by the organizational members while implicit goals of the organizations are quite complex(Martin, 2010).

As the societies are getting more and more industrialized the purpose of organizational creation and goals is also getting complex(Rappa, 2003). It is because of this importance and complexity of organizational existence a fully established paradigm under the domain of OMT exists to overview organizations in detail and in order to understand these goals, a stream of research in the domain of organizational theory is paying attention to metaphors or images of the organizations, so that members can clearly identify their role. According to (Daft \& Wiginton, 1979; Drazin et al., 1999;Gioia, Schultz, \& Corley, 2000) metaphors and role of language have gained great attention in the organizational studies. Organizational image or metaphors are seen in a broader perspective which includes the concepts that how organization is perceived by others, (Dutton et al., 1994). Metaphors have gained great attention of academic interest as a tool for highlighting symbolic and ideational dimensions of organizational life(Morgan, 1983). 
Organizations all over the world are spotted with confusions and obscurities, (Morgan, 1983) and in order to scan them internally and externally images of organizations play a meaningful role. Up till now most agreed upon classifications of metaphors encapsulates nine metaphors listed by Morgan (1983). These organizational metaphors include machines, organisms, culture, brain, political systems, psychic prisons, flux and transformation and instruments of domination. Metaphors are helpful because they transmits enormous amount of information, (Yousefi) thus presenting the receiver with ideas and situations that provides the opportunity to understand the organizations in a better way.

Organizations as machines acts as rational enterprise which are designed and prearranged to achieve predetermined goals as competently as possible, using the one best possible solution to systematize and linear concept of cause and effect(Galbraith, 1974; Morgan \& Videotraining, 1997). Organizations as living organisms seek to adapt and survive in a changing environment. Organizations as brains are flexible, resilient and inventive(Calvin, 1994). Here, the capacity for intelligence and control is seen as being distributed throughout the enterprise, enabling the system as a whole to self-organize and evolve along with the emerging challenges(Takeuchi \& Umemoto, 1996; Zeleny, 1977). Organizations as cultures act as minisocieties, with their own distinctive values, rituals, ideologies and beliefs(Scott, 1961). Organizations acts as an ongoing procedure of realism construction, which allows people to see and comprehend particular events, actions, objects, comments and situations in distinct ways(March, 1962). Organizations acts as systems of political activity in political system, with patterns of competing interests, conflict and power(Mintzberg, 1985). As psychic prisons organizations acts as systems that get trapped in their own thoughts and actions; and in which obsessions, mind traps, narcissism, strong emotions, illusions of control, anxieties and defense mechanisms become the focus of attention(Walsham, 1991). In flux and transformation, organizations acts as expressions of deeper processes of transformation and change(Taber, 2007). While acting as Instruments of Domination, organizations proceed as systems that exploit their employees, the natural environment and the global economy for their own ends; exposing the ethical and social dimensions as important points of focus(Morgan, 1980).

In today's world of uncertainty the success of an organization depends more than ever on the importance and usage of strategic planning and strategy formulation in achieving the ever desired business results(Godet, 2000; Godet \& Roubelat, 1996). In other words, "If you don't know where you are going, any road will take you there "(David \& Hall, 1998) implies the significance of the strategic planning.

All firms are competing with one another for gaining sustainable competitive edge over each other(Galbraith, 1973; Garud \& Kotha, 1994). Sustainable competitive edge can only be gained by responding rapidly to the changes in environment and meeting the customer demands(Anderson \& Rosenfeld, 1993; Arbib, 2005; Beer, 1972;Hedberg \& jöhsson, 1977). This requires strategy formulation on regular basis and it can be done only if organization acts as a brain(Rumelt, 1998). Brain has the ability to self-organize and responds quickly to the broad range of external stimuli. Taking the lead from this line of thought our argument is that the emergent school of strategy which also focuses on strategy formulation on emergent and regular basis (McDermott \& O'Connor, 2002; Mintzberg \& Waters, 1985) is directly linked to brain metaphor of the organizations as strategies will emerge according to the changes in environment and brain will act as a focal point for strategy formulation (Dyer, 1983). 
It is of little doubt that all of these metaphors provide useful insights to the organizations, their makeup and their goals(Ashforth \& Mael, 1989). Which metaphor is more useful to provide a deeper insight is coined to the scenario which needs attention and is at hand; hence to comment which metaphor is more effective is beyond the scope of this paper. The primary objective of this paper is to review process of strategy formulation with the help of grounded theory of images of the organizations. Taking the lead from Morgan's conceptualization of Metaphors or images this theoretical paper aims to use images of the organization as a framework for strategy formulation and in this back drop raises the following research questions.

1- How organizations are conceived?

2- $\quad$ What are the various images of the organizations?

3- $\quad$ How images of the organizations can be used to formulate the strategies?

4- What is the relevance of using brain as a metaphor for strategy formulation?

\section{Literature Review}

\section{Self-organization and the brain}

The process of "Self-organization" is defined in terms of systems that are in general comprises of many parts that impulsively attain their structure or function without specific intrusion from an external agent(Dutton et al., 1994). Example of self-organization is provided by the growth of plants and animals. Another example is the creation of a sculpture by an artist(Haken, 2008).

The concept of self-organization was first discussed in ancient times in Greek philosophy (Paslack, 1991). Moreover, in more modern times, self-organization was discussed by the German philosopher Immanuel Kant (Paslack, 1991), who specifically dealt with the formation of the planetary system, as well as by the German philosopher Schelling (Paslack, 1991), whose discussion remains rather weak. In more modern times, self-organization was discussed by Heinz von Foerster (1992) within his book "Cybernetics of second order". A systematic study of selforganization phenomena is performed in the interdisciplinary field of synergetic(Haken, 2008) that is concerned with a profound mathematical basis of self-organization as well as with experimental studies of these phenomena.

The phenomenon of self-organization is found everywhere in living and non-living world. But at this point the research paper provides a predominantly interesting example, explicitly self-organization phenomena of the human brain. The human brain is one of the most composite systems that we all know in the world. It is composed of up to 100 billion neurons and glia cells which are strongly interconnected. For example, a single neuron can have more than 10,000 associations to the other neurons. The question to be asked is who or what steers the various neurons so that they can generate macroscopic trend such as the logical navigation of muscles in locomotion, grasping, visualization that is in particular pattern identification and decision making(Drazin et al., 1999). An early proposal that the human brain acts as a selforganizing system according to the laws discovered by synergetic was presented by H. Haken in 1983. The explicit example of Gait transitions of horses were conceived as non-equilibrium phase transitions studied in synergetic that provide an explicit example of self-organizing phenomena. A similar suggestion was made in the context of dissipative structures by(Haag \& Kaupenjohann, 2001; Kelso, Holt, Rubin, \& Kugler, 1981;Kohonen, 1988). 


\section{Brain Metaphor}

Most of the firms compete in industries that require quick responses to the changing environment and technology. Due to increase in customer demand new products are manufactured on continual basis. A human brain is capable of responding constantly to the changing environment. Brain can create new repertoires of behaviors and perception as it become accustomed to the change in environment (Garud \& Kotha, 1994). Brain can learn new languages and its ability to self-organize makes it capable to respond quickly to wide range of external stimuli (Arbib, 2005). Due to these characteristics researchers are inspired to use brain as a metaphor in strategy formulation in order to respond the broad range of stimuli (Beer, 1972; Garud \& Kotha, 1994).

\section{Brain at Analogical Level}

Most of the researchers suggest that the ability of brain to process information in parallel and dispersed is due to its layered structure that manner makes it to take action swiftly against the change in environment (Anderson \& Rosenfeld, 1993; Arbib, 2005; Calvin, 1994). A group of similar type of neurons is fired through parallel processing which integrates the input and generates an output (see Figure 1). The generated output either excites or stops the activities of

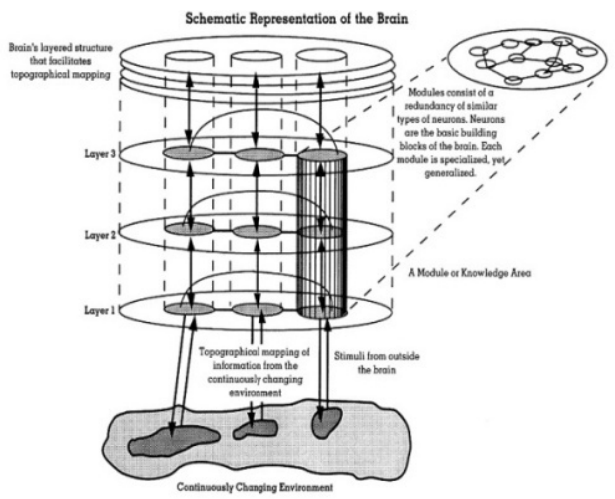

other neurons by means of synapses that create electrochemical connectivity among neurons (Anderson \& Rosenfeld, 1993). Topographical is another feature of brain that promotes parallel processing and boost flexibility because it allows the transformation of complex information in parallel (Anderson \& Rosenfeld, 1993; Arbib, 2005; Argyris, 1976; Beer, 1972; Calvin, 1990)

Source: Garud, R., \& Kotha, S. (1994). Using the brain as a metaphor to model flexible production systems. Academy of Management Review, 678.

Brain also performs several functions that are dispersed over other parts of brain's anatomy. In brain no prior estimation of operating parameters are made because it continuously changes with the environment. Brain tunes its operating parameters (Arbib, 2005) by updating its operating parameters that preside over the information transformation into insights and action. 


\section{Strategy Formulation}

The art and science of formulating, implementing and evaluating strategy is broadly defined as strategic management (David \& Hall, 1998). Although the scholars and practitioner believe that strategic management and resulting strategy is an important contributor to the firm performance. But till to date it is still debatable that in which form strategic management contributes to firm performance, in this line we claim that strategic management has not yet become a robust paradigm of studying organizational performance.

As the various schools has emerged over the time defining strategic management and resulting performance of the firm (e.g. Emergent school by Mintzberg and Planning school by Ansoof) hence the claim that strategic management has become a fully established paradigm is still debatable (Ansoff, 1987) and needs an extensive empirical evidence. In the words of Kuhn a paradigm is unanimously recognized scientific achievements that, for a time period, provide problems and solutions for a community of researchers(Kuhn, 1996)". In this view if strategic management has become a fully established paradigm it must answer the relationship of strategic management with the performance in all contexts and types of the organization. With this notion the present study aims to examine the power of strategic management as a fully established paradigm of formulating strategy and resulting performance of the firm and further it will be interesting to discuss images of the organization as a tool for strategy formulation.

The strategy formulation is like coping with the beast and for the managers in today's word of uncertainty the beast is unmanageable until or unless they will use certain analytical tools that can proactively analyze the environmental uncertainty (Greenley, 1986, 1994; Mintzberg, 1990; Mintzberg, Ahlstrand, \& Lampel, 2005). Thus strategic planning is a proactive approach that helps an organization to find a better position in an uncertain world (Amram \& Kulatilaka, 1999; D. C. Eadie, 1983; D.C. Eadie, 2000) with the desired goal of reducing the implicit gap between current position of an organization and where it wants to be (Bryson, 1988, 2011; Gooderham, 1998).According to Eadie (2000) strategic planning is the centripetal force and is an organized process which helps to generate information about the environmental uncertainty and translates the organizational goals into practical objectives .Hence strategic planning helps to permeate the organizational culture and develops the intuition of managers about where we are now and where we want to go (Osborne, 1993). In Greenley's $(1986,1994)$ opinion there are two fundamental reason of strategic planning in the organizations first strategic planning improves the performance second it improves the organizational effectiveness.

Even when the immediate returns on application and use of strategic planning are not evident but in an uncertain environment, the usage of strategic management and strategic planning tools to remain competitive is not an option any more (Calantone, Garcia, \& Dröge, 2003; Christensen, 1985; White, 1986). It is believed by the scholars that strategic management and usage of strategic planning for the strategy formulation is mandatory decision in front of mangers to cope with the serious challenges that organizations have been experiencing (Aldehayyat \& Anchor, 2008; Paulraj \& Chen, 2007). The organizations that use strategic planning as a compass to navigate through the turbulent environment develop a unique strategy and as a result gain competitive advantage (Wilson, 1998). 


\section{Various schools of thoughts on Strategy Formulation}

The strategy literature is overwhelmed with various views of scholars and practitioners on effective formulation of strategy (Poister \& Streib, 2005; Poister \& Streib, 1999; Porter, 1996;Porter \& Millar, 1985). But there are three schools that predominantly overshadow the strategy formulation process namely intuitive school and analytical or planning school and cognitive school (Mintzberg, 1990; Mintzberg et al., 2005; Mintzberg \& Lampel, 1999; Nutt, 1984; Poister \& Streib, 1999; Rindova \& Kotha, 2001).

\section{Intuitive School}

The central of every decision is intuition(Mintzberg et al., 2005). Intuition is not an irrational phenomenon rather it is the deep understanding of a particular situation(Mckenna, 1999; Mintzherg, 1999). The chief role of manager in an organization is to formulate strategies(Liedtka \& Rosenblum, 1996). The future is dependent on the strategic process and is created through the strategic planning which comes from the intuition of managers (Gooderham, 1998; Simpson, 1998a, 1998b;Sjöberg, 2003). It is the intuition not the in depth analysis that leads to the strategy formulation(Simon, 1987; Zimmerman, 1990) in the organizations as intuition is quick, automatic and it allows the manager to know what is the best course of action(Mintzberg et al., 2005).

\section{Analytical School}

According to analytical schools an effective strategy is not the result of intuition only as it is the amalgamation of manager's insight towards backward and forward circumstances (Houlden, 1995). The analytical schools asserts that to look five years ahead, organization must look ten years backward so that effective trends can be analyzed and as a result effective strategies can be formulated (Desai, 2000; Schriefer, 1998). Here the underpinning logic is that relying on intuition is not enough organizations must analyze the uncertainty in the form of trends (Mintzberg et al., 2005). For analytical analysis of trends, organizations need tools and methodologies that can effectively analyze the environment (Amram \& Kulatilaka, 1999). Hence the logic to successful planning is to get the best fit between the chosen tools and techniques, the organization's current culture, capabilities and business environment and the desired outcome (Gooderham, 1998).

\section{Cognitive School}

According to cognitive school, strategies are developed in people's mind as frames, models, concepts and schemas(Sørensen \& Vidal, 2006). From 1980s till today research has grown steadily on cognitive biases in strategy making and on cognition as information processing, knowledge structure mapping and concept attainment(Mintzherg, 1999). All these play an important role in strategy formulation. The other branch of cognitive school has adopted a more subjective interpretative or constructivist view of the strategic process(Mintzberg et al., 2005). According to cognitive school, cognition is used to construct strategies (Haken, 2008)as creative interpretations rather than simply to map reality in some or more objective way.

\section{Brain as a framework of strategy formulation}

As discussed in the previous sections strategy formulation is a complex phenomenon and requires deep insights from the managers of the organizations. In this view it seems logical that brain can be used a framework for strategy formulation as when organizations are considered as brain they solely rely on their human resources to formulate strategies that can best meet the 
objectives of the organizations. Hence cognitions of the individuals will be reflected in the process of strategy formulation and brain will act a self reflective mechanism that will guide the future of the organizations.

Discussion

The challenges which today mangers have to face in the organizations are trends such as globalization, technology advancement, deregulation, emerging of new markets and industries, and economic restructuring have greatly increased the organization's need to develop its unique strategy (Aldehayyat \& Anchor, 2008; Douglas \& Craig, 1989; Kotabe \& Murray, 2004).The historical discourse of OMT leads us to the time of Aristotle who for the first time used various metaphors for discussing the social phenomenon. Similar to this line of thought today OMT has been accustomed to the usage of various metaphors to discuss the organizational phenomenon.

The strategy which is at the heart of organizational success is discussed in this paper through a metaphor of brain. We are of the view that if organizations have to survive in today's changing environment they have to use the cognition of individuals in their process of strategy formulation. According to cognitive school, people perceive and processes information regarding the changes in external environment. A strategy in cognitive school emerges as frames of realities using the self reflection of brain to cope uncertain environment. This cognitive school then requires individual's insights in to whole process. Hence brain which is the self reflecting tool can be a guiding parameter for effective strategy formulation.

There is a need for organization's attention in this regard where extensive training and more empowerment to the individuals is required so that they can be used to employ brain while defining the process of strategy formulation. A useful guide in this connotation can be(Argyris, 1976) frame work of organizational learning where individuals through the process of single and double learning can be accustomed to use their brains so that past mistakes can be rendered and future strategies can be formulated in more effective manner.

\section{Conclusion}

Following set of conclusions can be drawn from this study. Organic organizations can be more successful and competitive if they can use brain as a framework for strategy formulation. Images of the organizations can be used to set forth the new dimensions of strategy formulation in the paradigm of strategic management. Self reflection of the organizations can be more helpful to cope with the external environment as the organizations that are in touch with the uncertainty of environment and plan effectively through self reflection and can have a competitive advantage as they are in a position to develop an effective strategic plan aligned with the objectives of the

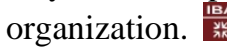

\section{References}

Aldehayyat, J. S., \& Anchor, J. R. (2008). Strategic planning tools and techniques in Jordan: awareness and use. Strategic Change, 17(7 8), 281-293.

Amram, M., \& Kulatilaka, N. (1999). Uncertainty: the new rules for strategy. Journal of Business Strategy, 20(3), 25-29.

Anderson, J. A., \& Rosenfeld, E. (1993). Neurocomputing (Vol. 1): The MIT Press. 
Ansoff, H. I. (1987). The emerging paradigm of strategic behavior. Strategic Management Journal, 8(6), 501-515.

Arbib, M. (2005). Modules, brains and schemas. Formal Methods in Software and Systems Modeling, 153-166.

Argyris, C. (1976). Single-loop and double-loop models in research on decision making. Administrative Science Quarterly, 363-375.

Ashforth, B. E., \& Mael, F. (1989). Social identity theory and the organization. Academy of management review, 20-39.

Beer, S. (1972). Brain of the firm: A Development in Management Cybernetics: Herder and Herder.

Broom, G. M., Casey, S., \& Ritchey, J. (1997). Toward a concept and theory of organizationpublic relationships. Journal of Public Relations Research, 9(2), 83-98.

Bryson, J. M. (1988). A strategic planning process for public and non-profit organizations. Long Range Planning, 21(1), 73-81.

Bryson, J. M. (2011). Strategic planning for public and nonprofit organizations: A guide to strengthening and sustaining organizational achievement (Vol. 1): Jossey-Bass.

Calantone, R., Garcia, R., \& Dröge, C. (2003). The effects of environmental turbulence on new product development strategy planning. Journal of Product Innovation Management, 20(2), 90103.

Calvin, W. H. (1990). The cerebral symphony: Seashore reflections on the structure of consciousness: Bantam Books.

Calvin, W. H. (1994). The emergence of intelligence. Scientific American, 271(4), 100-107.

Christensen, K. S. (1985). Coping with uncertainty in planning. Journal of the American Planning Association, 51(1), 63-73.

Daft, R. L., \& Wiginton, J. C. (1979). Language and organization. Academy of Management Review, 179-191.

David, F. R., \& Hall, P. P. (1998). Strategic management: Concepts and cases. Journal Entry, 5, 2.

Desai, A. B. (2000). Does strategic planning create value? The stock market's belief. Management decision, 38(10), 685-693.

Douglas, S. P., \& Craig, C. S. (1989). Evolution of global marketing strategy: scale, scope and synergy. Columbia Journal of World Business, 24(Fall), 47-59.

Downs, A., Durant, R., \& Carr, A. N. (2003). Emergent strategy development for organizations. Emergence, 5(2), 5-28.

Drazin, R., Glynn, M. A., \& Kazanjian, R. K. (1999). Multilevel theorizing about creativity in organizations: A sensemaking perspective. Academy of Management Review, 286-307.

Dutton, J. E., Dukerich, J. M., \& Harquail, C. V. (1994). Organizational images and member identification. Administrative Science Quarterly, 239-263. 
Dyer, L. (1983). Bringing human resources into the strategy formulation process. Human Resource Management, 22(3), 257-271.

Eadie, D. C. (1983). Putting a powerful tool to practical use: The application of strategic planning in the public sector. Public Administration Review, 43(5), 447-452.

Eadie, D. C. (2000). Change in Chewable Bites. Handbook of Strategic Management, 2.

Galbraith, J. R. (1973). Designing complex organizations: Addison-Wesley Longman Publishing Co., Inc.

Galbraith, J. R. (1974). Organization design: An information processing view. Interfaces, 4(3), 2836.

Garud, R., \& Kotha, S. (1994). Using the brain as a metaphor to model flexible production systems. Academy of Management Review, 671-698.

Gioia, D. A., Schultz, M., \& Corley, K. G. (2000). Organizational identity, image, and adaptive instability. Academy of Management Review, 63-81.

Godet, M. (2000). The Art of Scenarios and Strategic Planning:: Tools and Pitfalls. Technological forecasting and social change, 65(1), 3-22.

Godet, M., \& Roubelat, F. (1996). Creating the future: the use and misuse of scenarios. Long Range Planning, 29(2), 164-171.

Gooderham, G. (1998). Debunking the myths of strategic planning. CMA Magazine, 72(4), 24-26.

Greenley, G. E. (1986). Does strategic planning improve company performance? Long Range Planning, 19(2), 101-109.

Greenley, G. E. (1994). Strategic planning and company performance: an appraisal of the empirical evidence. Scandinavian Journal of Management, 10(4), 383-396.

Haag, D., \& Kaupenjohann, M. (2001). Parameters, prediction, post-normal science and the precautionary principle-a roadmap for modelling for decision-making. Ecological modelling, 144(1), 45-60.

Haken, H. (2008). Self-organization of brain function. Scholarpedia, 3(4), 2555.

Hedberg, B., \& jöhsson, S. (1977). Strategy formulation as a discontinuous process. International Studies of Management \& Organization, 7(2), 88-109.

Houlden, T. (1995). How corporate planning adapts and survives. Long Range Planning, 28(4), 910.

Kelso, J. A. S., Holt, K. G., Rubin, P., \& Kugler, P. N. (1981). Patterns of human interlimb coordination emerge from the properties of non-linear, limit cycle oscillatory processes: Theory and data. Journal of motor behavior, 13(4), 226-261.

Kohonen, T. (1988). An introduction to neural computing. Neural networks, 1(1), 3-16.

Kotabe, M., \& Murray, J. Y. (2004). Global sourcing strategy and sustainable competitive advantage. Industrial Marketing Management, 33(1), 7-14.

Kuhn, T. S. (1996). The structure of scientific revolutions: University of Chicago press. 
Liedtka, J., \& Rosenblum, J. (1996). Shaping conversations. California Management Review, 39(1), 141-157.

March, J. G. (1962). The business firm as a political coalition. The Journal of Politics, 24(04), 662-678.

Martin, R. L. (2010). The execution trap. Harvard Business Review, 88(7/8), 64.

McAuley, J., Duberley, J., \& Johnson, P. (2007). Organization theory: Challenges and perspectives: Prentice Hall.

McDermott, C. M., \& O'Connor, G. C. (2002). Managing radical innovation: an overview of emergent strategy issues. Journal of product innovation management, 19(6), 424-438.

Mckenna, S. (1999). Learning through complexity. Management Learning, 30(3), 301-320.

Mehregan, M. R., Kahreh, M. S., \& Yousefi, H. Strategic Planning by use of Total Systems Intervention Towards the Strategic Alignment.

Mintzberg, H. (1985). The organization as political arena. Journal of Management Studies, 22(2), 133-154.

Mintzberg, H. (1990). The design school: reconsidering the basic premises of strategic management. Strategic Management Journal, 11(3), 171-195.

Mintzberg, H., Ahlstrand, B., \& Lampel, J. (2005). Strategy safari: A guided tour through the wilds of strategic management: Free Pr.

Mintzberg, H., \& Lampel, J. (1999). Reflecting on the strategy process. Sloan Management Review, 40, 21-30.

Mintzberg, H., \& Waters, J. A. (1985). Of strategies, deliberate and emergent. Strategic management journal, 6(3), 257-272.

Mintzherg, H. (1999). Reflecting on the strategy process.

Morgan, G. (1980). Paradigms, metaphors, and puzzle solving in organization theory. Administrative Science Quarterly, 605-622.

Morgan, G. (1983). More on metaphor: Why we cannot control tropes in administrative science. Administrative Science Quarterly, 28(4), 601-607.

Morgan, G., \& Videotraining, K. I. (1997). Images of organization (Vol. 16): Wiley Online Library.

Nutt, P. C. (1984). Planning process archetypes and their effectiveness. Decision Sciences, 15(2), 221-238.

Osborne, D. (1993). Reinventing government. Public Productivity \& Management Review, 349356.

Paslack, R. (1991). Urgeschichte der Selbstorganisation: zur Archäologie eines wissenschaftlichen Paradigmas: Vieweg. 
Paulraj, A., \& Chen, I. J. (2007). Environmental uncertainty and strategic supply management: a resource dependence perspective and performance implications. Journal of Supply Chain Management, 43(3), 29-42.

Poister, T. H., \& Streib, G. (2005). Elements of strategic planning and management in municipal government: Status after two decades. Public Administration Review, 65(1), 45-56.

Poister, T. H., \& Streib, G. D. (1999). Strategic management in the public sector: Concepts, models, and processes. Public Productivity \& Management Review, 308-325.

Porter, M. E. (1996). What is strategy?

Porter, M. E., \& Millar, V. E. (1985). How information gives you competitive advantage. Harvard Business Review, 63(4), 149-160.

Rappa, A. L. (2003). A Critique of Modernity: On Positivism, and Phenomenology. Alternatives: Turkish Journal of International Relations, 2(3\&4).

Rindova, V. P., \& Kotha, S. (2001). Continuous" morphing": Competing through dynamic capabilities, form, and function. Academy of management journal, 1263-1280.

Ringberg, T., \& Reihlen, M. (2008). Towards a Socio Cognitive Approach to Knowledge Transfer. Journal of Management Studies, 45(5), 912-935.

Rumelt, R. P. (1998). Evaluating business strategy. Mintzberg H, Quinn JB, Ghoshal S., The Strategy Process, Revised Edition, Prentice Hall Europe.

Schriefer, A. (1998). The future trends discontinuities, and opportunities. Strategy \& Leadership, 26(1), 26-31.

Scott, W. G. (1961). Organization theory: an overview and an appraisal. The Journal of the academy of Management, 4(1), 7-26.

Selznick, P. (1948). Foundations of the Theory of Organization. American sociological review, 13(1), 25-35.

Simon, H. A. (1987). Making management decisions: The role of intuition and emotion. The Academy of Management Executive (1987-1989), 57-64.

Simpson, D. G. (1998a). Why most strategic planning is a waste of time and what you can do about it. Long Range Planning, 31(3), 476-480.

Simpson, D. G. (1998b). Why most strategic planning is a waste of time and what you can do about it--part II. Long Range Planning, 31(4), 623-627.

Sjöberg, L. (2003). Intuitive vs. analytical decision making: which is preferred? Scandinavian Journal of Management, 19(1), 17-29.

Sørensen, L., \& Vidal, R. V. V. (2006). Creativity and Strategy Development. IMM, Technical.

Stinchcombe, A. L. (2000). Social structure and organizations.

Taber, T. D. (2007). Using metaphors to teach organization theory. Journal of Management Education, 31(4), 541-554. 
Takeuchi, H., \& Umemoto, K. (1996). A theory of organizational knowledge creation. International Journal of Technology Management, 11, 7(8), 833-845.

Walsham, G. (1991). Organizational metaphors and information systems research. European Journal of Information Systems, 1(2), 83-94.

Weber, M. (1997). The theory of social and economic organization: Free Pr.

White, R. E. (1986). Generic business strategies, organizational context and performance: An empirical investigation. Strategic Management Journal, 7(3), 217-231.

Wilson, I. (1998). Strategic planning for the millennium: Resolving the dilemma. Long Range Planning, 31(4), 507-513.

Yousefi, M. Organizational Metaphors.

Zeleny, M. (1977). Self-organization of living systems: A formal model of autopoiesis. International journal of general system, 4(1), 13-28.

Zimmerman, B. J. (1990). Self-regulated learning and academic achievement: An overview. Educational psychologist, 25(1), 3-17.

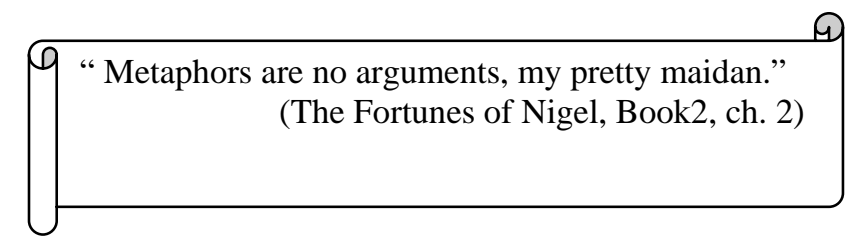

